\title{
Factors influencing a physical education teacher's pedagogical games practices with pupils experiencing social, emotional and mental health
}

issues

Nick O'Leary, Carl Longmore, Richard Medcalf

\section{Abstract}

Recognizing the limited research examining physical education teachers' pedagogical practices for pupils experiencing social, emotional and behavioural issues, this case study sought to examine how a male teacher with a high performing sports background taught games to such pupils and identify those factors that led to such practices. Occupational socialization was used to explore how childhood experiences of physical education and high performance sport, higher education and the workplace influenced his teaching and learning approaches in a special school setting. Data were collected by conducting three semi-structured interviews, eight videoed lesson observations and a self-reflective journal. Inductive data analysis identified that the twin aims of developing life skills and transferability of such skills beyond physical education were said to be achieved by developing pupils' emotional resilience and encouraging appropriate social behaviour. The influence of the teacher's family, his high performing sporting background, the needs of the pupils and the school's policies impacted on developing such resilience and social behaviour. Two suggestions are offered as a result of these findings. Firstly, prior examination of childhood values should be undertaken for those wishing to teach physical education to pupils experiencing social, emotional and mental health issues. Secondly, given this study contradicts research findings that teachers with high performing sport backgrounds emphasize the development of pupils' practical performance, research examining the impact of such sportspersons on physical education pedagogy in different educational settings appears warranted.

\section{Introduction}

In the United Kingdom (UK), the Special Educational Needs and Disability Act (Department for Education and Employment (DEE), 2001) requires schools to provide pupils experiencing social, emotional and mental health (SEMH) issues opportunities to participate in physical education (PE). The benefits of PE to such pupils with 'a learning difficulty or disability which calls for special educational provision' (Department for Education (DfE), 2014: 15) have been well documented. For example, Medcalf et al. (2006) argue that the ever-changing nature of the PE environment provides greater opportunities for physical, cognitive and social learning than classroom-based subjects. This dynamic and fluid environment can also help 'overcome' the potential disruptive behaviour of such pupils (Morley et al., 2005). Moreover, a reduction in disruptive behaviour following PE lessons has also been reported (Medcalf et al., 2011). It should be recognized that while many pupils experiencing SEMH issues excel in PE (Bailey, 2009), others find it difficult due to a complex array of behavioural issues.

SEMH issues are considered to be the manifestation of dominant communication and interaction conditions such as autism spectrum disorder (ASD), attention deficit and hyperactivity disorder (ADHD) (Sellman, 2009) and, more recently, anxiety and depression (Carroll and Hurry, 2018). Pupils 
in PE lessons experiencing ASD and ADHD can present 'external' (delinquent or aggressive) or 'internal' (withdrawn, anxious or social) behavioural issues (Nelson et al., 2003). A number of key factors appear to potentially impact on such behaviours. The pupil can have an antipathy to PE resulting in the subject having no relevance to him/her. The child can feel threatened by the social dominance of their peers. Pupils on the periphery of social groups may produce extreme behaviour to win and/or antagonise dominant peer groups. Differing standards at home, in school and in different subject classrooms can cause tension and confusion. The public exposure of physical deficiencies can result in pupil anxiety, and impulsive behaviour can arise that is unintentional in nature (Cohen et al., 2010). Generic teaching and learning strategies to help overcome these factors are well documented. Individualized teaching, the giving of clear instructions and positive feedback, consistent and routine behavioural expectations, engaging activities, achievable learning outcomes, smooth transitions between tasks, a relaxed atmosphere, a positive reaction to behavioural issues, equality of pupil treatment and appropriate differentiation are well known (see Medcalf et al., 2011; Winnick and Porretta, 2017). Whilst specific PE pedagogical approaches for differing emotional, behavioural and social issues such as ADHD are limited (Healy et al., 2013), learning within a social context may help overcome the 'external' or 'internal' behavioural concerns highlighted above (Medcalf et al., 2011; Reeves and Bailey, 2014).

Social development for pupils with SEMH issues based on a 'humanistic' approach, focussing on human needs and values as opposed to solely practical aptitude and skill development, has gathered momentum (Loovis, 2017). Examples such as use of the 'responsibility' model and 'social stories' are seen to have the potential to develop new practical skills, promote desired social behaviours and consider how skills learned during PE can be transferred into life (see Hellison, 2011; Sandt, 2008; Sumalot-Riveriera and Porretta, 2013). The implementation of such innovative pedagogical practices to encourage holistic learning in PE appears to be the result of teachers' past and current experiences working in education and sport (Curtner-Smith et al., 2008; O'Leary et al., 2014; Stran and Curtner-Smith, 2009).

\section{The occupational socialization framework}

Occupational socialization describes the different types of socialization that influence people to enter the PE profession and how they are socialized into the role of a teacher (Lawson, 1986). In defining this theoretical framework, Lawson (1986) makes a number of primary assumptions about the process. Firstly, PE teachers' socialization is a life-long process beginning during childhood. Secondly, pedagogical practices are institutionalized, resulting in less-experienced teachers reproducing the 'trusted' practices of their more experienced PE colleagues. Thirdly, socialization is problematic rather than automatic. While higher education institutions, schools and colleagues may attempt to 'mould' teachers' pedagogical practices, teachers may reject or partially/fully accept the contents of this process (Zeichner and Gore, 1990). The outcomes of this dialectic process (Schempp and Graber, 1992) are likely to be the result of the fourth assumption, which identifies that PE (student) teachers encounter three phases of occupational socialization (Lawson, 1986). Acculturation, referring to childhood experiences of PE and sport, is the first phase. Usually identified as the most influential stage (Curtner-Smith et al., 2008), beliefs internalized from family, PE teachers and/or sport coaches become dominant and common sense in nature (Lortie, 1975).

Such subjective theories of reality can screen out inconsistent perceptions while allowing consistent perceptions to be incorporated with the individual's existing worldview (Richards et al., 2014). 
However, there is evidence that these relatively stable beliefs can be amended as the individual passes through the three stages of occupational socialization, accumulating new experiences and interacting with new socializing agents (O'Leary, 2015).

While primary socialization within the family (Lacey, 1977) has been seen to have a significant impact on the decision to enter the teaching profession, its impact on specific teaching and learning practices appears limited (Su, 1992). In contrast, the influence of the secondary socialization factors outside the family (Lacey, 1977), such as PE teachers and sport coaches, appears to influence pedagogical practices in a significant way. O'Leary et al. (2015) found a female teacher's games practices with a class of year nine boys experiencing SEMH issues was heavily influenced by her childhood activity experiences. In contrast, a case study investigating a PE teacher's use of the Teaching Games for Understanding model (Bunker and Thorpe, 1982) with pupils experiencing SEMH issues revealed the acculturation stage had minimal impact on his teaching practices (O'Leary et al., 2014). While the influence of the acculturation stage on PE teachers' pedagogical practices with pupils experiencing SEMH issues appears contested, research indicates beliefs acquired during childhood are likely to act as sieves screening out inconsistent perspectives while further reinforcing consistent perspectives (Richards et al., 2014). Sport may have a more profound impact on reinforcing such perspectives than $\mathrm{PE}$ teachers given time spent in PE is likely to be minimal in comparison to sporting opportunities inside and outside school (Evans, 1992).

Sport socialization appears to produce PE teachers with conservative values. Evans (1992) identified a 'sporting perspective' emphasizing the development of practical competency and a desire to develop the already high performing child. This perspective emphasizes the acquisition of techniques and skills via progressive drills accompanied by technical teaching points. It has been suggested that teachers with a high performing sports background are more likely to emphasize the development of practical competency using such pedagogical approaches (Richards and Padaruth, 2017). However, the potential influence of sport coaches and PE teachers during the acculturation stage for teachers of children who experience SEMH is far from straightforward. Given the acculturation phase lacks direct experience of SEMH issues for most potential PE teachers, this 'absence of apprenticeship' may result in the university/teacher education forming a 'salvaged' phase upon which to base teaching and learning approaches (Pugach, 1992).

The influence of university/teacher education or professional socialization upon prospective teachers' pedagogical practices is often considered relatively limited given the powerful impact of PE and particularly sport from the previous phase (Stran and Curtner-Smith, 2009). However, the impact of the professional phase for students who gain experience supporting or interacting with pupils who experience SEMH issues during their undergraduate degree and/or one-year PostGraduate Certificate in Education (PGCE) or graduate teaching programme following their degree may be much greater. The 'absence of an apprenticeship of observation' during the acculturation stage identified above, coupled with relevant regulations and a technical language based around SEMH instruction, means the professional phase may have a very strong socializing effect upon teachers instructing pupils experiencing SEMH issues (Pugach, 1992; Young, 2008). 
Organizational socialization can be described as the influence of the school and the process by which one learns a specific role within the workplace (Van Maanen and Schein, 1979). Whilst acknowledging the potential impact of parents (O'Leary et al., 2014) and senior school staff/administrators (Richards and Templin, 2011), research indicates that teaching colleagues and pupils have the most influential impact on PE teachers' pedagogical practices in SEMH settings (O'Leary et al., 2014, 2015; Sato and Haegele, 2016). O'Leary et al. (2014) identified that a fellow colleague largely reinforced a newly qualified teacher's use of the Teaching Games for Understanding model, indicating the early impact of the 'institutional press' (Zeichner and Gore, 1990) on teachers' practices. Nonetheless, the influence of colleagues may be less than that of the pupils. O'Leary et al. (2015) identified that a female PE teacher's approaches were heavily influenced by her desire for compliant and engaged pupils. In contrast, O'Leary et al. (2014) found that a male $P E$ teacher's practices were influenced by the learning needs of the pupils. However, he acknowledged that the pupils' excellent behaviour allowed him to justify his use of appropriate lesson structure and boundaries, high levels of physical activity and the development of pupil problem-solving and reflective abilities. In short, learning needs and the potential behavioural issues of pupils experiencing SEMH issues appear to heavily impact on PE teachers' pedagogical practices.

\section{The current study}

The rationale for conducting this research was multi-faceted. Firstly, this study responds to the fact that research examining how PE teachers instruct pupils experiencing SEMH issues is limited. Identifying how such pedagogical practices impact on fulfilling the aims and objectives of school and departmental policies should be of critical interest to head teachers, heads of department and (PE) teachers themselves. Research identifying those factors that influence such pedagogical approaches is also limited, particularly in a special school setting (Healy et al., 2013; O'Leary et al., 2014, 2015; Sato and Haegele, 2016). Secondly, this research responds to the request of Sato and Haegele (2016), who suggest all three phases of occupational socialization should be considered in attempting to identify factors that influence pedagogical practices with pupils with SEMH issues, particularly since the impact of the acculturation stage is contested (O'Leary et al., 2014, 2015; Pugach, 1992). Finally, while the impact of sport on pedagogical practices in mainstream settings has been partially examined (Jayantilal and O'Leary, 2016; O'Leary, 2015), the influence of a high performing sport background on teachers' pedagogical approaches in an SEMH school is conspicuous by its absence. The potential over-emphasis upon practical competency (Richards and Padaruth, 2017) rather than considering, for example, the necessary social development for pupils experiencing SEMH issues (Loovis, 2017; Medcalf et al., 2011; Reeves and Bailey, 2014) should be of interest to head teachers and PE teachers. For these reasons, the purposes of this research study were to examine how a PE teacher with such a background taught games to pupils with SEMH issues and identify those factors that led to such teaching and learning practices.

\section{Methodology}

\section{Philosophical position}

This constructivist-interpretive study attempted to create an understanding of the constructions of a male PE teacher underpinned by relativist ontology with a subjectivist epistemology (Denzin and Lincoln, 2011). In short, we sought to interpret his views of how he taught games to pupils with SEMH issues in his usual 'classroom' setting and those factors that he felt impacted on his pedagogical practices. The use of a qualitative single-participant case study design (Yin, 2013) and 
the occupational socialization framework (Lawson, 1986) would provide multiple sources of in-depth data rich in context (Creswell, 2013) in order to address the purposes of the study.

\section{The research site}

The Hub School (a pseudonym), the case study site, is an urban community special school for pupils aged 5-19 years situated in Yorkshire, UK. During the study the school population was 195. Fortynine per cent of pupils were from minority ethnic backgrounds. Thirty per cent of pupils did not have English as their home language. Fifty-seven per cent of pupils were eligible for the Pupil Premium, which provides additional funding for those pupils in local authority care or already receiving a free school meal. All pupils have a statement of special educational needs or an education, health and care plan (additional assistance beyond special educational needs support). The majority of pupils have moderate learning difficulties (MLD) combined with behavioural difficulties and ADHD.

School documentation such as the behaviour and assessment/target setting policies emphasize the need for pupils to acquire basic functional skills, personal and social skills and the self-regulation and management of their emotions in readiness for moving on to a college setting. The core values of the school are to listen when the teacher is speaking, be pleasant to others, be safe and try to stay on task. Amongst other responsibilities, teachers are expected to promote good behaviour and act as positive role models. The most recent Office for Standards in Education (Ofsted) report in 2013 rated the school as outstanding in all areas inspected (achievement of pupils, teaching, leadership and management, and behaviour and management of pupils).

PE is a compulsory subject in the school. Lessons are taught by one of the three specialist staff supported by either one or two educational teaching assistants. Pupils receive two PE lessons per week. A unit of work usually consists of eight lessons. The current secondary PE programme of study was devised to meet the requirements of the National Curriculum of Physical Education (NCPE) (Qualifications and Curriculum Authority (QCA), 2007). For example, the teachers recognize that most pupils should have the ability to plan and adapt strategies in games, although some pupils with specific issues may only be able to practise skills and actions in sequence and combination. There is also a specific focus on developing social and leadership skills.

\section{The participant's biography}

The following details of the participant were generated during the initial interview (see data collection methods below). Joseph (a pseudonym) is a 41-year-old British white male. During his childhood his mother was a dancer and choreographer, while his father played football. He recalled primary school sports days 'because I enjoyed winning from an early age'. Secondary school PE lessons were 'structured and you would learn something from those lessons'. During his secondary school years, Joseph attended local football and basketball clubs that were 'always well organized and encouraged competition'.

Joseph completed a Bachelor of Science Honours degree in Health and Sport Studies. He remarked that 'there were only a few sessions that I was taught to teach and coach, and they were kind of an 
introduction to how to plan a session'. Following his degree studies, Joseph completed a graduate teaching programme. This consisted of working three days a week in an Emotional and Behavioural Difficulties (EBD) school and two days a week at a mainstream sports college. Joseph's mentors at both schools 'prioritized skill development and behavioural standards'. Throughout his studies, he coached his chosen sport in schools and camps, focussing largely on improving players' performance. As a high performing sportsman, Joseph has represented England 24 times and won 11 national titles at various levels.

Joseph has taught for 12 years in five SEMH schools. He has spent five years teaching at the Hub School. Currently, he is Head of PE and Head of Key Stage 4. He suggested that a year 11 class (aged 15-16 years) of 10 pupils should be observed for data collection purposes. He felt it was an ideal class to observe given that the six males and four females in the class exhibited a variety of learning difficulties including SEMH and MLD, and two of the boys have been diagnosed with ADHD. During the data collection period the class were being taught basketball. Prior to research being undertaken, consent forms outlining the aims of the study and detailing the methodology and handling of data were provided to Joseph, the head teacher and parents. They were informed that participation in the study was voluntary and all data would be treated as strictly confidential. Throughout dissemination of the study, the participants' entitlement to privacy and rights to confidentiality and anonymity were guaranteed (British Educational Research Association (BERA), 2011).

\section{Data collection methods}

To produce a reconstructed understanding of the participating teacher's pedagogical games practices, data was collected using semi-structured interviews, videoed lesson observations (VLO) and a self-reflective journal. This took place between September 2016 and April 2017.

\section{Semi-structured interviews}

Three semi-structured interviews were conducted with the teacher in his home. They provided an opportunity to gain in-depth responses and allow Joseph to recreate his experiences (Lincoln and Guba, 1985). The initial interview (II) took place prior to games lessons being taught. The purposes of this 75-minute interview were to provide the researchers with a detailed biography of Joseph and identify possible factors influencing his teaching and learning approaches. Joseph's acculturation, professional socialization and organizational socialization were explored. Specific questions examined the potential influence of his family, school teachers, sports coaches, university lecturers, teaching colleagues and school policies on his current pedagogical practices. Lesson two was used to conduct a stimulated recall interview (SRI). The camera angles and views were determined by the educational teaching assistant filming the lessons. This 63-minute interview would provide additional data on his teaching and learning practices and, crucially, allow Joseph to explain how he acted in specific pedagogical episodes and why (Dempsey, 2010). The final interview (FI) took place after the VLO. This 47-minute interview sought to identify how factors from Joseph's childhood experiences of PE and high performance sport, higher education and the workplace influenced his pedagogical approaches observed in the VLO. Specific questions included what he felt the pupils should learn in games lessons and what had influenced his emphasizing pupils working well with others, challenging themselves, and showing individual and collective responsibility. 


\section{Videoed lesson observations}

The eight 30-minute lessons that comprised the games unit of work were filmed by an educational teaching assistant. VLO were utilized because the social interplay between teacher and pupils is complex and difficult to capture through non-participant observation and field notes (Ward and Quennerstedt, 2016). Repeated viewing of video footage by the first named researcher allowed notes to be taken. Acting as sensitizing concepts, the benchmarks shown in Table 1 were constantly referred to in order to provide an initial focus of key incidents to be highlighted (Jayantilal and O'Leary, 2016).

Table 1. Observation sheet.

Table 1. Observation sheet.

General SEMH pedagogical strategies

Use of clear instructions

Display and encourage appropriate social skills

Consistent and routine behavioural expectations

Provide achievable outcomes

Ensure pupil equality

Provide appropriate challenges

Use differentiation

Appropriate use of equipment

Ensure smooth and well-timed transitions

Use positive feedback reinforcement

Additional ADHD pedagogical strategies

Use alternative rules

Use peer tutoring

Explore learning opportunities to control the body and temper

Encourage pupils to work in teams

Focus on transferability of learned skills into aspects of life beyond PE/games

Use opportunities for observable learning

NCPE games learning outcomes

Select and combine skills and techniques accurately and appropriately

Comment and compare skills and techniques and how these are applied in their own and others' work

Use and show what they know about strategy and tactics to produce effective outcomes

Source: (Adapted from Bailey, 2009; Bishop and Block, 2012; Healy et al., 2013; Hellison, 2011; Medcalf et al., 2011; Pan et al., 2011; QCA, 2007; Vidoni, 2003; Winnick and Porretta, 2017).

SEMH: social, emotional and mental health; ADHD: attention deficit and hyperactivity disorder; NCPE: National Curriculum of Physical Education.

\section{Self-reflective journal}

Recognizing that written words can often be more illuminating than spoken words given the additional 'thinking-time' available to the participant (Mason, 2002), Joseph was asked to complete a self-reflective journal (SRJ). Following each lesson, Joseph was asked to note what was taught, how it was taught and why it was taught. He was asked to report on satisfying and dissatisfying experiences, issues encountered and to note any additional points he felt were important during the lessons. 


\section{Data analysis}

Given the exploratory nature of the study, data were analysed using a general inductive approach (Thomas, 2006) and constant comparison (Patton, 2002). In attempting to make sense of field data from the three data sources, the researchers independently identified specific units of text and these were sorted into initial categories. The researchers discussed the potential influence of these initial categories and, as a result, they were reduced in number until only provisional themes remained (Creswell, 2013). During the development of the provisional themes, each unit of text was constantly compared to other data to confirm or disconfirm the finding. The provisional themes acted as a foundation to re-read the data several times and subsequently recode the data where appropriate to produce a reduced number of final themes. This process was completed firstly in relation to the teacher's pedagogical games practices, and secondly with regard to how his occupational socialization had influenced these practices.

\section{Results and discussion}

Interpretation of the teacher's pedagogical games practices

Joseph implemented many general SEMH pedagogical strategies, including providing appropriate challenges (Bailey, 2009; Winnick and Porretta, 2017), encouraging appropriate social skills and providing a relaxed atmosphere in which to work (Cohen et al., 2010; Harvey et al., 2012). Additional ADHD teaching and learning strategies were also evident. Joseph provided opportunities for observable learning and peer tutoring, encouraged pupils to work in teams and focussed upon the transferability of learned skills into aspects of life beyond PE (Harvey et al., 2012; Healy et al., 2013; Pan et al., 2011). Inductive analysis and constant comparison of the three data sources identified that Joseph emphasized the development of life skills and their transferability beyond the immediate 'classroom'. These two aims were achieved via two overriding themes that influenced Joseph's pedagogical games practices: developing pupils' emotional resilience and encouraging appropriate social behaviour.

\section{Theme 1: developing pupils' emotional resilience}

Joseph wanted the pupils to have a positive outlook and the ability to recover from difficult emotional experiences (Davidson, 2000). To achieve this he constantly challenged the pupils, stating, 'overcoming the challenges is more important than the skill because I know they will get the skill if they overcome the little things that go with it' (SRI). He was 'happy' to see them fail in his lessons, commenting, 'you want them to fail in PE, help them deal with it, and then say, "when you go into that other lesson, that might be tough, but you can do it"' (FI). He challenged the pupils physically and cognitively.

Physically challenging the pupils by working hard was important to Joseph. In VLO 5 he asked the class, 'do you want to give up?' They replied no, and he responded by saying, 'that is a great answer'. He valued physical effort over technique or skill acquisition. Joseph told the class, 'I have a lot of time for Mary (a pseudonym). This is tiring and she is keeping going. A lot of kids would stop' (VLO 4). A positive outlook was also required when he challenged the pupils cognitively. Joseph informed the class, 'these are simple passing techniques but remembering the order is becoming increasingly more complex' (VLO 3). Despite the pupils sometimes forgetting the order of the techniques required, he continued to encourage them to keep trying. He commented that 'a lot of the problems 
they have stem from their inability to meet challenges. I'm always saying, "so what if that's happened, what are you going to do about it?"' (SRI). Such responsibility was also expected in terms of behaviour.

\section{Theme 2: encouraging appropriate social behaviour}

Joseph encouraged appropriate behaviour in three ways. Firstly, individual responsibility was expected. Secondly, pupils were expected to be able to work well with their peers. Finally, Joseph modelled appropriate social behaviour himself.

Joseph expected pupils to show individual responsibility. He asked them, 'if I wasn't here, would you be able to run this lesson?' (VLO 2). During VLO 3 he stated, 'it should not need me to organize you' (VLO 3). While there were times when pupils needed to be reminded of their responsibilities, they demonstrated a high level of responsibility. In VLO 4, 'one pupil left the gym and his partner carried on working on his game'. Joseph was not concerned when individual pupils briefly left the lesson to get a drink of water, commenting, 'they are a responsible class and rarely take advantage of the situation when I cannot see them' (SRI). During VLO 2, 'Joseph turned his back on the group for a minute while he discussed the music to be played with his assistant, indicating he clearly trusted the group'. Indeed, Joseph's trusting nature may have encouraged the pupils to show even greater responsibility. Such responsibility was also evident when pupils worked with and alongside their peers.

Joseph felt appropriate social behaviour benefitted everyone, commenting, 'teamwork relies on everybody working well together' (VLO 5). If their behaviour was irresponsible in other classes, Joseph would remind them of the need to 'think of other people in your lessons' (VLO 3). Comments throughout the SRJ, such as, 'the way in which they work together and help each other is inspiring' (SRJ L4), were commonplace. However, on occasions, opportunities for pupils to show individual and collective responsibility for their actions were reduced. The NCPE (QCA, 2007) requirement for pupils to plan and adapt tactics and strategies in games was limited. Comments such as 'you've got to see different things and make the right decision' (VLO 5) throughout the eight lessons indicated that Joseph understood the importance of decision-making in the ever-changing environment that games present (Kirk and MacPhail, 2002). Despite this, he sometimes took responsibility away from the pupils by telling them what skills they should use and what decisions they should make.

Joseph clearly felt he had a responsibility to model appropriate behaviour, stating, 'I like teaching because I have an influence in being a role model' (II). He was grateful that the pupils had consented to being filmed, saying, 'thank you for this. I really appreciate it' (VLO 1). Such positive group reinforcement was also given to individual pupils. He told one pupil 'you wouldn't have done that before and you would have given up' (VLO 1). Demonstrating individual responsibility and facing challenges himself, Joseph went in the middle to play defender in the 'piggy-in-the-middle' game (VLO 7). In congruence with school documentation such as the behaviour policy, Joseph stated, 'I hope my behaviour and desire to "give it a go" will improve their behaviour inside and outside the $P E$ "classroom" and stop them worrying about mistakes and failing' (II). 
The relevance of emotional resilience and appropriate social behaviour to other lessons and postschool was continually emphasized. Reflecting on how he taught VLO 3, Joseph wrote, 'I framed the lesson on issues during the week regarding behaviour for learning of this class in other lessons' (SRJ, L3). In the same lesson he remarked, 'we never have problems here. Why can't this be the case in other lessons?' He also acknowledged that attempting to overcome challenges in PE should take place in other lessons. In VLO 1, after seeing a pupil persevere with a challenging task, he told the class, 'If you found something difficult to do in maths or English, you should always give it a go'.

The relevance of facing challenges and demonstrating appropriate social behaviour outside school and post-school was also made apparent to the pupils. A pupil bouncing a basketball when Joseph was addressing the class was met with, 'what would that be like in a restaurant, it would be chaos. It's just a matter of manners' (VLO 1). Reflecting on the eight lessons taught, he wrote, 'when pupils leave school they understand the need to work hard and how to value people' (SRJ, L8). Figure 1 summarizes Joseph's pedagogical games practices.

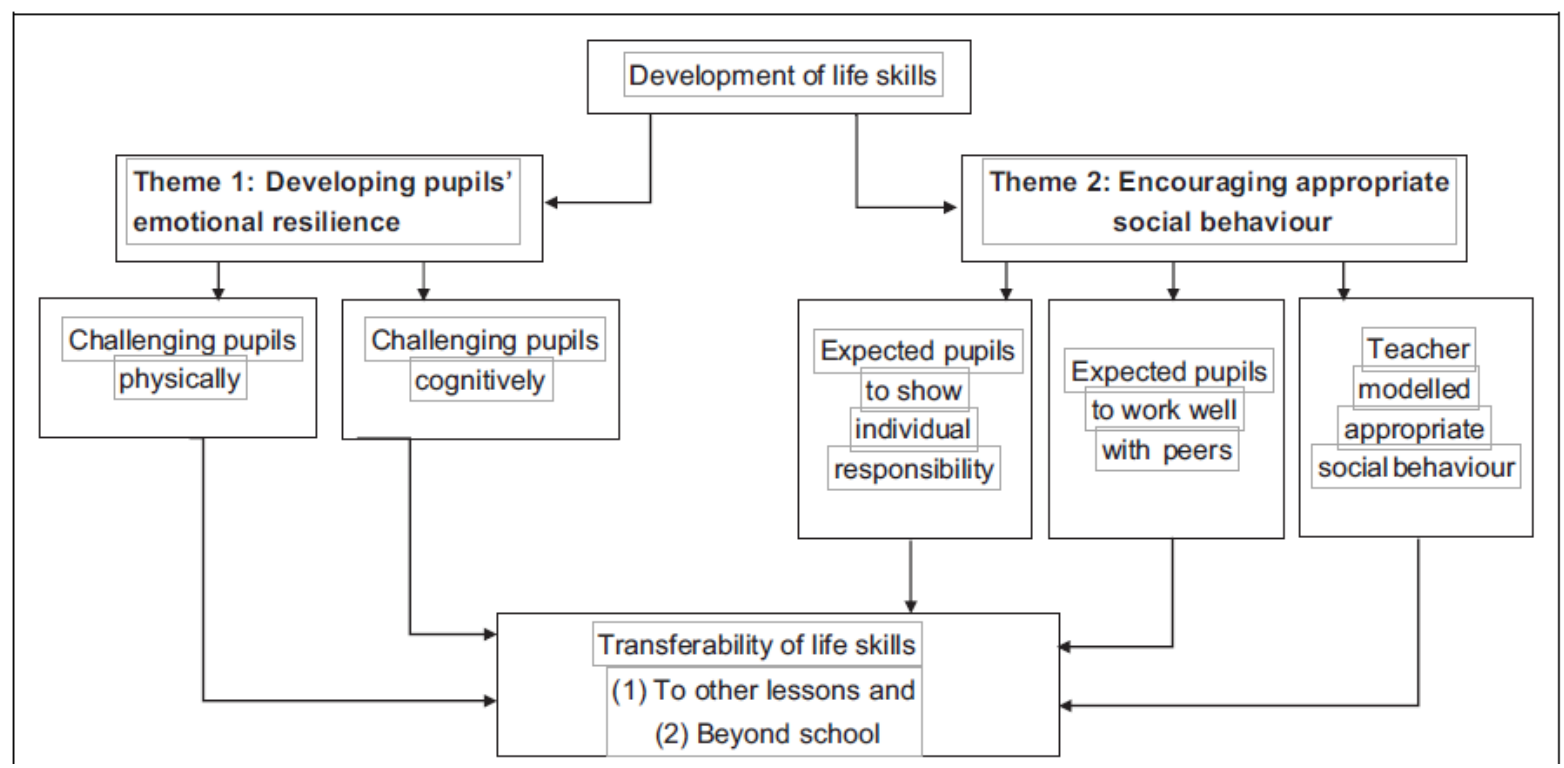

Figure 1. Interpretation of the teacher's pedagogical games practices.

We now turn our attention to those factors that influenced those teaching and learning practices.

\section{Factors influencing the teacher's pedagogical games practices}

The acculturation and organizational stages of the occupational socialization framework appear dominant in terms of their impact on Joseph's pedagogical practices. There were four prominent themes that influenced Joseph's emphasis upon developing the pupils' emotional resilience and appropriate social behaviour: the influence of his family; his high performing sporting background; the needs of the pupils and the school's policies (see Table 2). 
Table 2. The teacher's pedagogical games practices and factors influencing such practices.

Delivery of games Sub-themes

Factors influencing delivery of games

A. Developing pupils' emotional resilience

B. Encouraging appropriate social behaviour

I. Challenging pupils physically

2. Challenging pupils cognitively

I. Pupils to show individual responsibility

2. Pupils to work well with their peers

3. Teacher modelled appropriate social behaviour

Family background

The high performing sporting background

The needs of the pupils Family background

The high performing sporting background

The needs of the pupils Family background

The high performing sporting background

School policies School policies

The high performing sporting background

The high performing sporting background

The needs of the pupils

School policies

\section{Theme 1: the influence of his family}

The impact of primary socialization on Joseph's educational values appears to have been extremely powerful (Lacey, 1977; Su, 1992). The influence of his family encouraged Joseph to take the pupils out of their comfort zone physically and cognitively, accept failure as part of the learning process and take responsibility for their actions. Joseph stated, 'my father would encourage me to get out of my comfort zone at certain times to learn something new - why would you learn something you already know?' (II). He wanted pupils to understand that by being taken out of their comfort zone they would learn and ultimately improve. The values of his family also encouraged Joseph to emphasize individual pupil responsibility.

Joseph commented that his parents and his own children have influenced his desire that pupils work responsibly with and without each other. He commented, 'what I want for my kids is a reflection of what I teach. It started with my father valuing doing the best for yourself and your teammates' (II). It was also evident that Joseph learned from his parents the importance of trust to encourage responsibility:

In the classroom I ask them, 'you tell me where is the best place for you to work', because if you do that they don't have an excuse to be irresponsible when working. At home I had a say in how things 
were sorted out. My parents trusted me, and you did not want to blow that. Respect lasts forever, fear doesn't (FI).

The influence of Joseph's family background on the above pedagogical practices were reinforced by the secondary socialization (Lacey, 1977) values that he acquired as a result of his involvement in high performance sport.

\section{Theme 2: the high performing sporting background}

Despite playing sport at a high level and working three days a week during the professional phase in an SEMH school with a teaching practice mentor who emphasized skill development, Joseph did not possess a 'sporting perspective' focussing on practical competency that has been found in UK mainstream settings (Evans, 1992; Jayantilal and O'Leary, 2016). Instead, in congruence with his family values, the nature of high performance sport influenced him to challenge the pupils, whilst the leadership skills developed through sport encouraged Joseph to emphasize appropriate social behaviour.

Joseph believed that by competing you are succeeding, and this would allow the pupils to be successful in school and throughout their lives:

Our kids don't need to fail, they need to succeed. Through competition you can emphasize that, ok, you didn't win that game but you are winning by competing. In our first year at college we only won three games. No one ever says to me now, 'you only won three games'. Instead they say, 'you were tough and you were getting there'. These kids have to know that they're just not there in life yet, but they will be there, they will get a job and be successful (II).

Joseph saw pupils failing in tasks as an opportunity for them to succeed by firstly, not giving up and secondly, overcoming the problems they faced. The need for the pupils to keep trying emanated from Joseph's high performing sporting past. Discussing one of his childhood sports coaches who recognized his talents, Joseph realized, 'from there on it was just hard work, so I had to be there before everybody else, leave after everyone else. You have to have a challenge for the kids to realize that's what it takes to be successful' (II). The challenging nature of his sporting background also underpinned his desire to encourage appropriate social behaviour.

Discussing his lack of size and speed for his chosen sport, Joseph recognized the need to do other things well. He compared this point with the pupils' academic limitations, acknowledging that 'they're not going to get five GCSEs, so they need to be good with people' (SRI). He added, 'if you go to another country playing another team and it's hostile...the ability to get on with people is crucial, so I emphasize it in my lessons' (SRI). An ability to work well with others was not exclusive to the pupils. 
Joseph's desire to model appropriate social behaviour stemmed from his sporting past. His early successes in high performance sport gave him leadership status amongst his peers:

Once you've played for England aged 20 and you go to a Division One team at 24, everyone is looking at you to be the leader. You kind of step out of your own body and watch yourself. I'm constantly thinking 'how do I look?' and 'how do I come across to the kids?' (II).

Joseph recognized that his successes in sport gave him a powerful position in influencing others and this has impacted on how he models his own social behaviour. He believed that being polite, giving praise and using humour in lessons earned him respect from the pupils. He stated, 'it's like playing for a coach: if you respect him and he gives you the time, then you respect him. You play for him. You're not going to play for someone who scares you into doing stuff' (II). This was particularly important given the needs of the pupils.

\section{Theme 3: the needs of the pupils}

The pedagogical approaches adopted by Joseph were child-centred. In congruence with O'Leary et al. (2014), he recognized the learning needs for EBD and MLD pupils with low self-esteem and, as a result, used positive reinforcement and acknowledged it was acceptable to fail in order to learn. Discussing a female pupil with MLD and very low self-esteem, he stated:

I'm smiling at her all the time and I'm saying, 'nothing you can do in here is going to be wrong', so she's alright. If I say, 'that's a bad pass', I'll also say to her, 'I still like you though'. Every kid I deal with differently (SRI).

Joseph felt the pupils needed to work hard in order to overcome the issues they faced in order to be successful in other lessons and life generally. However, he suggested they still have to learn to deal with errors. Discussing his emphasis upon the pupils trying to remember progressively more difficult drills, Joseph argued that pupils forgetting on occasions gave them an opportunity to try and remember what was required and demonstrate appropriate individual and social behaviour.

Joseph recognized the amenable nature of the class, and in contrast to the research findings of O'Leary et al. (2015), he did not feel the need to consistently align his instructional approaches to ensure compliant pupils. However, he did acknowledge the character of each pupil regarding individual responsibility for their behaviour, stating, 'you might only have to say it once to some kids but you've got to reinforce it with certain kids constantly' (II). The need for appropriate individual and social behaviour was reinforced by various school policies.

\section{Theme 4: the school's policies}

The school and aligned PE policies emphasized the development of life skills and their transferability beyond school life. Joseph commented that such policies emphasized the need for pupils to 'show 
progress of social skills, to show leadership, to show behaviour for learning' (FI). He followed these policies, encouraging pupils to be individually responsible for their actions and work well with each other. The various policies also required him to model appropriate social behaviour. He took advantage of the varied opportunities in PE to act as a role model (Sellman, 2009; Sumalot-Riviera and Porretta, 2013) and provide opportunities for pupils to demonstrate desired social skills (Medcalf et al., 2011; Vidoni, 2003). However, on occasions, Joseph took individual and collective responsibility away from the pupils by informing them what skills they should use and how game problems might be solved (Kirk and MacPhail, 2002). Whilst acknowledging Joseph's games knowledge and the sound SEMH pedagogical practices observed (Bailey, 2009; Harvey et al., 2012; Winnick and Porretta, 2017), greater opportunities for the pupils to fulfil the NCPE (QCA, 2007) requirement to solve strategies and tactics in games is desirable.

\section{Conclusions}

This study supports Lawson's (1986) assumption that PE teachers' socialization is a life-long process. Whilst accepting Joseph's childhood lacked direct experience of pupils with SEMH, the impact of his family and high performing sport background instilled a number of values that reinforced his pedagogical practices aimed at developing the pupils' emotional resilience and social behaviour (Richards et al., 2014; Su, 1992). In turn, these two themes were critical in fulfilling school and PE policy requirements. As a result, Joseph's teaching and learning practices followed the institution's desired practices and appeared to be 'automatically' implemented (Zeichner and Gore, 1990).

The findings above are based on a single-participant case study over a relatively short time scale (eight months). The occupational socialization framework may not totally capture how socially constructed definitions of PE are negotiated and how the role of the teacher is developed (see Richards, 2015; Richards et al., 2013). In recognizing these limitations, a number of take-home messages are evident. Firstly, the fact that acquired values underpin pedagogical practices suggests, in agreement with O'Leary et al. (2014), that prior examination of such values by those employing PE teachers in an SEMH school is warranted. Secondly, the need to ensure acquired values are in congruence with school and departmental policies appears essential to help ensure the smooth implementation of such policies. Thirdly, the assumption that experience interacting with pupils with SEMH issues during university studies/placements may have a strong socializing effect upon PE teachers' pedagogical practices (Young, 2008) is not supported by this study. In contrast to the acculturation and organizational phases, the professional phase appears to have had little influence on Joseph's teaching and learning approaches. Finally, in contrast to beliefs suggesting that a high performing sports background can result in an over-emphasis upon practical competency (Richards and Padaruth, 2017) rather than the required holistic development of pupils with SEMH issues (Loovis, 2017; Medcalf et al., 2011; Reeves and Bailey, 2014), this research indicates this need not be the case. It appears this is dependent on the 'lessons' learned from high performance sport and their similarity to school policy aims. Research examining the impact of high performing sportspeople in other SEMH and mainstream settings on PE teaching practices and pupils' learning appears warranted. 


\section{Declaration of Conflicting Interests}

The authors declared no potential conflicts of interest with respect to the research, authorship and/or publication of this article.

\section{Funding}

The authors received no financial support for the research, authorship and/or publication of this article.

\section{References}

Bailey R (2009) Teaching Physical Education: A Handbook for Primary and Secondary School Teachers. Abingdon: Routledge.

Bishop J and Block M (2012) Positive illusory bias in children with ADHD in physical education. Journal of Physical Education, Recreation and Dance 83(9): 43-48.

British Educational Research Association (BERA) (2011) Ethical Guidelines for Educational Research. Available at: http://www.bera.ac.uk/researchersresources/publications/ethical-guidelines-foreducationall-research-2011 (accessed 9 August 2016).

Bunker D and Thorpe R (1982) A model for the teaching of games in secondary schools. Bulletin of Physical Education 18(1): 5-8.

Carroll C and Hurry J (2018) Supporting pupils in school with social, emotional and mental health needs: A scoping review of the literature. Emotional and Behavioural Difficulties 23(3): 310-325.

Cohen L, Manion L and Morrison K (2010) A Guide to Teaching Practice. London: Routledge.

Creswell JW (2013) Research Design: Qualitative, Quantitative and Mixed Method Approaches. London: SAGE.

Curtner-Smith MD, Hastie PA and Kinchin GD (2008) Influence of occupational socialization on beginning teachers' interpretation and delivery of sport education. Sport, Education and Society 13(1): 97-117.

Davidson RJ (2000) Affective style, psychopathology, and resilience: Brain mechanisms and plasticity. American Psychologist 55(11): 1196-1214.

Dempsey NP (2010) Stimulated recall interviews in ethnography. Qualitative Sociology 33(3): 349367.

Denzin NK and Lincoln YS (2011) The discipline and practice of qualitative research. In: Denzin NK and Lincoln YS (eds) The SAGE Handbook of Qualitative Research. London: SAGE Publications, pp.119.

Department for Education (DfE) (2014) The Code of Practice. 0-25 Years. London: DfE, HMSO.

Department for Education and Employment (DEE) (2001) Special Educational Needs and Disability Act 2001. London: DEE, HMSO.

Evans J (1992) A short paper about people, power and educational reform. Authority and representation in ethnographic research subjectivity, ideology and educational reform: The case of 
physical education. In: Sparkes A (ed.) Research in Physical Education and Sport: Exploring Alternative Visions. London: The Falmer Press, pp.231-247.

Harvey W, Wilkinson S, Presse C, et al. (2012) Children say the darndest things: Physical activity and children with attention-deficit hyperactivity disorder. Physical Education and Sport Pedagogy 19(2): 205-220.

Healy S, Mstefi R and Gallagher S (2013) Happy and a bit nervous: The experiences of children with autism in physical education. British Journal of Learning Disabilities 41(3): 222-228.

Hellison D (2011) Teaching Personal and Social Responsibility through Physical Activity. Champaign: Human Kinetics.

Jayantilal K and O'Leary N (2016) (Reinforcing) factors influencing a physical education teacher's use of the direct instruction model delivering games. European Physical Education Review 23(4): 392 411.

Kirk D and MacPhail A (2002) Teaching games for understanding and situated learning: Rethinking the Bunker-Thorpe model. Journal of Teaching in Physical Education 21(2): 177-192.

Lacey C (1977) The Socialization of Teachers. London: Methuen.

Lawson HA (1986) Occupational socialization and the design of teacher education programs. Journal of Teaching in Physical Education 5(2): 107-116.

Lincoln YS and Guba EG (1985) Naturalistic Inquiry. Thousand Oaks, California: SAGE.

Lortie DC (1975) School Teacher: A Sociological Study. Chicago, IL: University of Chicago Press.

Loovis EM (2017) Behaviour management. In: Winnick J and Porretta D (eds) Adapted Physical Education and Sport. Leeds: Human Kinetics, pp.101-119.

Mason J (2002) Qualitative Researching. London: SAGE.

Medcalf R, Marshall J and Rhoden C (2006) Exploring the relationship between physical education and enhancing behaviour in pupils with emotional behavioural difficulties. Support for Learning 21(4): 169-174.

Medcalf R, Marshall J, Hardman K, et al. (2011) Experiences and perceptions of physical education. Emotional and Behavioral Difficulties 16(2): 189-206.

Morley D, Bailey R, Tan J, et al. (2005) Inclusive physical education: Teachers' views of teaching children with special educational needs and disabilities in physical education. European Physical Education Review 11(1): 84-107.

Nelson R, Babyak A, Gonzalez J, et al. (2003) An investigation of the types of problem behaviors exhibited by $\mathrm{k}-12$ students with emotional or behavioral disorders in public school settings. Behavoural Issues 28(4): 348-359.

Office for Standards in Education (Ofsted) (2013) Find an Inspection Report. Report. Available at: http:// reports.ofsted.gov.uk/ (accessed 7 July 2016).

O'Leary N (2015) Learning informally to use the 'full version' of teaching games for understanding. European Physical Education Review 22(1): 3-22. 
O'Leary N, Longmore C and Medcalf R (2014) The influence of occupational socialisation upon a teacher's interpretation and delivery of teaching games for understanding to pupils experiencing social and emotional behavioural difficulties. Support for Learning 29(1): 57-75.

O'Leary N, Longmore C and Medcalf R (2015) The influence of occupational socialization upon the teaching of pupils experiencing social and emotional behavioural difficulties in physical education. Journal of Research in Special Educational Needs 15(4): 247-256.

Pan C, Tsai C and Hsieh K (2011) Physical activity correlates for children with autism spectrum disorders in middle school physical education. Research Quarterly for Exercise and Sport 82(3): 491498.

Patton MQ (2002) Qualitative Research and Evaluation Methods. London: SAGE.

Pugach M (1992) Uncharted territory: Research on the socialization of special education teachers. Teacher Education and Special Education 15(2): 133-147.

Qualifications and Curriculum Authority (QCA) (2007) Physical Education: Programme of Study for Key Stage 4. London: QCA.

Reeves M and Bailey R (2014) The effects of physical activity on children diagnosed with attentiondeficit hyperactivity disorder: A review. Education 3-13 44(6): 591-603.

Richards KAR (2015) Role socialization theory: The sociopolitical realities of teaching physical education. European Physical Education Review 21(3): 379-393.

Richards KAR and Padaruth S (2017) Motivations for pursuing a career in physical education: The rise of a fitness orientation. Journal of Physical Education, Recreation and Dance 88(4): 44-46.

Richards KAR and Templin TJ (2011) The influence of a state mandated induction assistance program on the socialization of a beginning physical education teacher. Journal of Teaching in Physical Education 30(4): 340-357.

Richards KAR, Templin TJ and Gaudreault KL (2013) Organizational challenges and role conflict: Recommendations for the preparation of physical education teachers. Quest 65(4): 442-457.

Richards KAR, Templin TJ and Graber K (2014) The socialization of teachers in physical education: Review and recommendations for future works. Kinesiology Review 3(2): 113-134.

Sandt D (2008) Social stories for students with autism in physical education. Journal of Physical Education, Recreation and Dance 76(9): 42-45.

Sato T and Haegele JA (2016) Graduate students' practicum experiences instructing students with severe and profound disabilities in physical education. European Physical Education Review 23(2): 196-211.

Schempp PG and Graber KC (1992) Teacher socialization from a dialectical perspective: Pretraining through induction. Journal of Teaching in Physical Education 11(4): 329-348.

Sellman E (2009) Lessons learned: Student voice at a school for pupils experiencing social, emotional and behavioural difficulties. Emotional and Behavioural Difficulties 14(1): 33-48.

Stran M and Curtner-Smith M (2009) Influence of occupational socialization on two preservice teachers' interpretation and delivery of the sport education model. Journal of Teaching in Physical Education 28(1): 38-53. 
Su Justine ZX (1992) Sources of influence in preservice teacher education. Journal of Education for Teaching 18(3): 239-258.

Sumalot-Riviera A and Porretta D (2013) The influence of social skills instruction on sport and game related behaviors of students with emotional or behavioral disorders. Physical Education and Sport Pedagogy 18(2): 117-132.

Thomas DR (2006) A general inductive approach for analysing qualitative evaluation data. American Journal of Evaluation 27(2): 237-246.

Van Maanen J and Schein EH (1979) Toward a theory of organisational socialization. In: Shaw B (ed.) Research into Organisational Behaviour. Greenwich, Connecticut: JAI Press, pp.209-261.

Vidoni C (2003) Teaching your class social skills: An explicit strategy. Teaching Elementary Physical Education 14(6): 20-23.

Ward G and Quennerstedt M (2016) Transactions in primary physical education in the UK: A smorgasbord of looks-like-sport. Physical Education and Sport Pedagogy 21(2): 137-152.

Winnick J and Porretta D (2017) Adapted Physical Education and Sport. Leeds: Human Kinetics.

Yin R (2013) Case Study Research: Design and Methods. London: SAGE Publications.

Young K (2008) An alternative model of special education teacher socialization. Teaching and Teacher Education 24(4): 901-914.

Zeichner KM and Gore JM (1990) Teacher socialization. In: Houston WR (ed.) Handbook of Research on Teacher Education. New York: MacMillan, pp.329-348. 